\title{
MEDIATING EFFECT OF JOB SATISFACTION ON THE RELATIONSHIP BETWEEN EMOTIONAL INTELLIGENCE AND PERCEIVED GENERAL HEALTH
}

\author{
LINGLING YUAN AND XUHUI TAN \\ Southern Medical University \\ CUNRUI HUANG \\ Griffith University \\ FEI ZOU \\ Southern Medical University
}

\begin{abstract}
We examined the mediating role that job satisfaction plays in the relationship between emotional intelligence (EI) and perceived general health. Participants were 124 faculty members in the School of Basic Medical Sciences at Southern Medical University, China. The simple path and fully mediated models were subjected to structural equation modeling. Results indicated that EI was positively correlated with job satisfaction, and that job satisfaction was positively correlated with perceived general health. However, when job satisfaction was controlled for, the partial correlation between EI and perceived general health became nonsignificant. Finally, we found that job satisfaction mediated the relationship between EI and perceived general health.
\end{abstract}

Keywords: emotional intelligence, job satisfaction, perceived general health, occupational psychology, structural equation modeling.

Lingling Yuan, Graduate School, Southern Medical University; Xuhui Tan; Department of Biostatistics, Southern Medical University; Cunrui Huang, Centre for Environment and Population Health, Griffith University; Fei Zou, Department of Occupational Health and Occupational Medicine, Southern Medical University.

Lingling Yuan and Xuhui Tan contributed equally to this study.

This work was supported by the National Natural Science Foundation of China (30971193, 81302515), the National Basic Research Program of China (2012CB518200), and Guangdong Natural Science Foundation (S2013040013902).

Correspondence concerning this article should be addressed to: Fei Zou, Department of Occupational Health and Occupational Medicine, Southern Medical University, 1838 North Guangzhou Avenue, Guangzhou, Guangdong 510515, People’s Republic of China. Email: txhyll@163.com 
Emotional intelligence, job satisfaction, and perceived general health are important concepts in occupational psychology (Arnold et al., 2005). Emotional intelligence is of particular importance for fields with a high requirement for competence in interpersonal communication, such as business negotiations and health care (Güleryüz, Güney, Aydın, \& Aşan, 2008; Jones \& Argentino, 2010). In addition, job satisfaction and perceived good general health are key to keeping employees work focused (Wright \& Cropanzano, 2000).

Salovey and Mayer (1990) were the first to posit the concept of emotional intelligence (EI), which they defined as "the subset of social intelligence that involves the ability to monitor one's own and others' feelings and emotions, to discriminate among them and to use this information to guide one's thinking and actions" (p. 189). In the second version of the Mayer-Salovey-Caruso Emotional Intelligence Test (MSCEIT V2.0), four branches of EI are assessed: (a) perceiving emotion accurately, (b) using emotion to facilitate thought, (c) understanding emotion, and (d) managing emotion (Mayer, Salovey, Caruso, \& Sitarenios, 2003). Other recent measures of EI are the Bar-On Emotional Quotient Inventory (Bar-On, 1997a, 1997b), the Emotional Intelligence Scale (Schutte et al., 1998), and the Work Profile Questionnaire-Emotional Intelligence Version (Cameron, 1999).

In recent years, the use of EI as a psychological determinant of occupational success has generated great interest in the field of occupational psychology. For instance, EI has been found to affect a variety of work behaviors, including teamwork, innovation, and customer loyalty (Zeidner, Matthews, \& Roberts, 2004). In the field of education, Ignat and Clipa (2012) found that teachers' strong EI was correlated with their positive attitude toward work, and work and life satisfaction, and in another study, results showed that teachers' EI significantly affected the quality of education they delivered (Birol, Atamtürk, Silman, \& Şensoy, 2009). In other studies, Birks and Watt (2007) found that food service employees and health care professionals with high EI were more likely to have higher levels of job satisfaction, and Güleryüz et al. (2008) regarded EI as a predictor of job satisfaction and organizational commitment.

The notion of job satisfaction was introduced by Hoppock (1935), after which Locke (1976) defined it as "a pleasurable or positive emotional state resulting from an appraisal of one's job or job experiences" (p. 1300). In other words, job satisfaction is how content an individual is with his or her job. Modern interest in job satisfaction began with Herzberg's (1968) two-factor theory, in which the focus is on intrinsic and extrinsic factors in the workplace. Recently, job satisfaction has received a substantial amount of attention. For example, the importance of job satisfaction to staff retention in healthcare organizations has been demonstrated in numerous studies (Duffield, Roche, O'Brien-Pallas, 
Catling-Paull, \& King, 2009; Giriyappa \& Sullivan, 2009; Hayne, Gerhardt, \& Davis, 2009; Tsai \& Hsu, 2008). Although job satisfaction is also thought to affect work performance (Robertson, Birch, \& Cooper, 2012), in a meta-analysis, Judge, Thoresen, Bono, and Patton (2001) suggested that the correlation between job satisfaction and productivity is tenuous. Nevertheless, Ignat and Clipa (2012) recognized job satisfaction as an important factor influencing teachers' work performance.

Perceived general health is essentially a self-reported general health status measured using the General Health Questionnaire (GHQ; Goldberg, 1978). Since its introduction, the GHQ has been the most common assessment of mental well-being, encompassing physical, emotional, and personal aspects (Bowling, 1997). It was designed to assess an individual's ability to carry out normal healthy functions, rather than screening for serious mental disorders. Of the various versions, the 28-item GHQ has been used most widely in working populations, allowing for more valid comparisons (Dale, Sævareid, \& Söderhamn, 2009). Some researchers have reported that job satisfaction could be an important factor influencing perceived general health. For example, Ríos-Risquez and GodoyFernández (2008) found that higher levels of job satisfaction were significantly associated with better general health among nurses.

However, although these researchers have examined the correlations among EI, job satisfaction, and perceived general health, a simple correlation among study variables is not sufficient to determine the mediating effect. In addition, little is known about the interrelationships of these factors among personnel whose jobs involve less interpersonal communication in an Asian cultural context, such as university faculty members in China. Therefore, our objective in this study was to examine the interrelationships between EI, job satisfaction, and perceived general health in faculty members at a Chinese medical university. A simple path model (Figure 1) was constructed based on the view that EI is a predictor of job satisfaction (Abraham, 2000) and that job satisfaction has a predominant role in maintaining good general health. We developed a fully mediated structural model (Figure 2) to explore the mediating effects of extrinsic and intrinsic job satisfaction on perceived general health. Thus, we proposed the following hypotheses:

Hypothesis 1: Emotional intelligence will be positively and significantly correlated with job satisfaction.

Hypothesis 2: Job satisfaction will be positively and significantly correlated with perceived general health.

Hypothesis 3: Job satisfaction will play a mediating role in the relationship between emotional intelligence and perceived general health. 


\section{Method}

\section{Participants}

Participants $(N=135)$ were selected randomly in 2013 from the 205 faculty members in the School of Basic Medical Sciences, Southern Medical University, China. To avoid common method bias, participants completed the measures of EI, job satisfaction, and perceived general health one at a time. After 2 months the second measure was completed, and the final measure was completed 4 months after the first measure. We received 124 fully completed and valid questionnaires, for a response rate of $92 \%$. Of these, 68 were men $(54.8 \%)$ and 56 were women $(45.2 \%)$ with ages ranging from 21 to 61 years $(M=35.61, S D=9.19)$.

\section{Measures}

Emotional intelligence. EI was measured with the 33-item Emotional Intelligence Scale developed by Schutte et al. (1998). The questionnaire items cover four domains: optimism/mood regulation (OMR), appraisal of emotion (AOE), social skills (SS), and utilization of emotion (UOE). Responses are recorded on a 5-point Likert-style scale ranging from 1 (strongly disagree) to 5 (strongly agree).

Job satisfaction. Job satisfaction was measured with the 20-item Minnesota Satisfaction Questionnaire short form (MSQ 20; Weiss, Dawis, England, \& Lofquist, 1967). The MSQ 20 is used to measure workers' satisfaction with 20 vocationally relevant need dimensions that include ability utilization, achievement, activity, advancement, authority, company policies and practices, and compensation. The items are divided into two subscales: intrinsic satisfaction and extrinsic satisfaction. Responses are recorded on the 5-point Likert-style scale used for the EI measure.

Perceived general health. Perceived general health was measured using the 28-item General Health Questionnaire (GHQ-28; Goldberg \& Williams, 1988). The GHQ-28 is a self-administered questionnaire used to assess an individual's well-being in two areas: the inability to carry out normal functions and the appearance of new and distressing phenomena. It consists of four subscales, each comprising seven items: somatic symptoms, anxiety and insomnia, social dysfunction, and severe depression. Responses are rated on a 4-point scale of severity ranging from 0 (less well than usual) to 3 (much worse than usual). Thus, scores for each subscale range from 0 to 21 points, and overall severity scores range from 0 to 84 , with lower scores indicating better health.

\section{Data Analysis}

A simple correlation analysis was performed on the study variables. Structural equation modeling (SEM) was used to assess the mediating effect of job 
satisfaction on the four EI dimensions and perceived general health. Several indices were calculated to evaluate the fit of the model to the data: chi square $\left(\chi^{2}\right)$, goodness of fit index (GFI), comparative fit index (CFI), normed fit index (NFI), and standardized root mean square residual (SRMSR). In all cases, a $p$ value less than .05 was considered to be significant. All data analyses were carried out using SAS/STAT ${ }^{\circledR}$ software version 9.2 (SAS Institute Inc., 2008).

\section{Results}

\section{Preliminary Analysis}

The descriptive statistics, reliability, and zero-order correlation coefficients for the study variables are shown in Table 1. Job satisfaction was significantly and positively correlated with all four EI dimensions (OMR, AOE, SS, and UOE), and EI was significantly and positively correlated with job satisfaction and negatively correlated with perceived general health (lower scores indicated better perceived general health because it was scored inversely). When job satisfaction was controlled for, the partial correlation between EI and perceived general health became nonsignificant $(p>.10)$. As can be seen in Table 1, all EI dimensions had inverse correlations with perceived general health and significant positive correlations with job satisfaction. That is, individuals with higher EI scores were more likely to have high levels of job satisfaction and to report a better perceived level of general health, than were individuals with lower EI scores.

Table 1. Correlation Matrix, Descriptive Statistics, and Reliability for the Study Variables

\begin{tabular}{|c|c|c|c|c|c|c|c|c|c|}
\hline Variable & EI & OMR & $\mathrm{AOE}$ & SS & UOE & JS & IJS & EJS & GH \\
\hline EI & 1 & & & & & & & & \\
\hline OMR & $.869^{* *}$ & 1 & & & & & & & \\
\hline $\mathrm{AOE}$ & $.879^{* *}$ & $.634^{* *}$ & 1 & & & & & & \\
\hline SS & $.919^{* * *}$ & $.711^{* * *}$ & $.743^{* *}$ & 1 & & & & & \\
\hline UOE & $.875^{* *}$ & $.786^{* * *}$ & $.685^{* *}$ & $.747^{* *}$ & 1 & & & & \\
\hline JS & $.550^{* * *}$ & $.509^{* * *}$ & $.500^{* *}$ & $.494^{* * *}$ & $.421^{* *}$ & 1 & & & \\
\hline IJS & $.516^{* *}$ & $.483^{* *}$ & $.464^{* * *}$ & $.465^{* *}$ & $.396^{* * *}$ & $.962^{* *}$ & 1 & & \\
\hline EJS & $.523^{* *}$ & $.476^{* *}$ & $.485^{* *}$ & $.469^{* *}$ & $.399^{* *}$ & $.919^{* *}$ & $.776^{* *}$ & 1 & \\
\hline $\mathrm{GH}$ & $-.306^{* *}$ & $-.354^{* *}$ & $-.203^{*}$ & $-.285^{* *}$ & $-.236^{* *}$ & $-.453^{* *}$ & $-.461^{* *}$ & $-.379^{* *}$ & 1 \\
\hline$M$ & 122.452 & 33.726 & 32.718 & 40.726 & 15.282 & 72.000 & 43.734 & 28.266 & 21.976 \\
\hline$S D$ & 14.856 & 4.148 & 4.786 & 5.258 & 2.530 & 9.878 & 6.187 & 4.272 & 8.658 \\
\hline$\alpha$ & .915 & .700 & .810 & .741 & .740 & .904 & .858 & .792 & .888 \\
\hline
\end{tabular}

Note. EI = emotional intelligence; $\mathrm{OMR}=$ optimism/mood regulation; $\mathrm{AOE}=$ appraisal of emotion; $\mathrm{SS}=$ social skills; UOE = utilization of emotion; JS = job satisfaction; IJS = intrinsic job satisfaction; EJS = extrinsic job satisfaction; GH = general health. $N=124 .{ }^{*} p<.05,{ }^{* *} p<.01$. 


\section{The Mediating Effect of Job Satisfaction on the Relationship Between El and} Perceived General Health

We tested the mediating effects in this study using SEM as recommended by Holmbeck (1997). The standardized direct path coefficients for the study model (Figure 1) are listed in Table 2. For example, to test the direct path from EI to perceived general health, the coefficient of the path from job satisfaction to perceived general health was constrained to zero. The direct path coefficients were all significant in the predicted directions. Next, the mediating effect was assessed under two conditions: (a) the direct path from EI to perceived general health was constrained to zero, and (b) the direct path from EI to perceived general health was not constrained. The results showed that the addition to the constrained model of the direct path from EI to perceived general health did not improve the fit ( $\Delta \chi^{2}$ was nonsignificant). As can be seen in Figure 1, a nonsignificant path $\left(p_{1}\right)$ was also found from EI to perceived general health. The findings suggested that job satisfaction had a mediating role in the relationship between EI and perceived general health.

Table 2. Direct Path Test

\begin{tabular}{lcc}
\hline Model: direct path & Standardized coefficient & $p$ \\
\hline $\mathrm{EI} \rightarrow \mathrm{GH}\left(p_{1}\right)$ & -.306 & $\leq .05$ \\
$\mathrm{E} \rightarrow \mathrm{JS}\left(p_{2}\right)$ & .550 & $\leq .05$ \\
$\mathrm{JS} \rightarrow \mathrm{GH}\left(p_{3}\right)$ & -.453 & $\leq .05$ \\
\hline
\end{tabular}

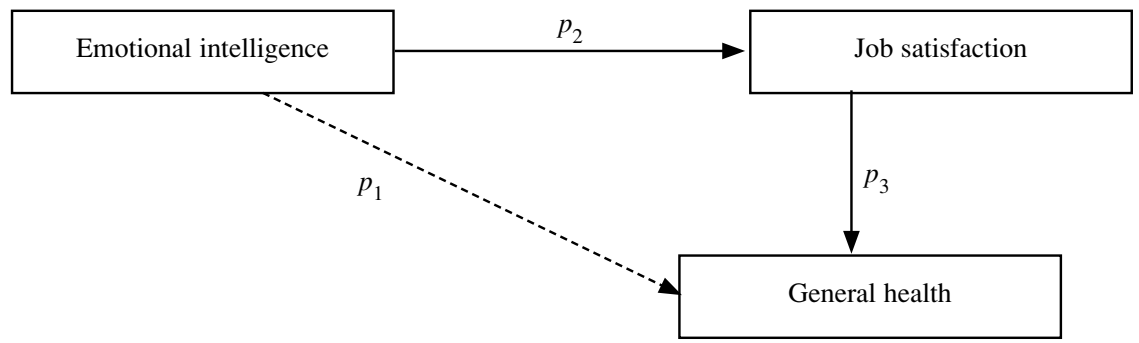

Figure 1. Hypothetical path model of the mediating effect of job satisfaction on El and perceived general health.

Note. Significant paths are shown with solid lines $\left(p_{2}\right.$ and $\left.p_{3}\right)$ and the nonsignificant path is shown with a broken line $\left(p_{1}\right)$.

\section{The Mediating Effect of Aspects of Job Satisfaction on the Relationship Between the El Dimensions and Perceived General Health}

Examination of the fully mediated structural model of the mediating effects of extrinsic and intrinsic job satisfaction on perceived general health (Figure 2) 

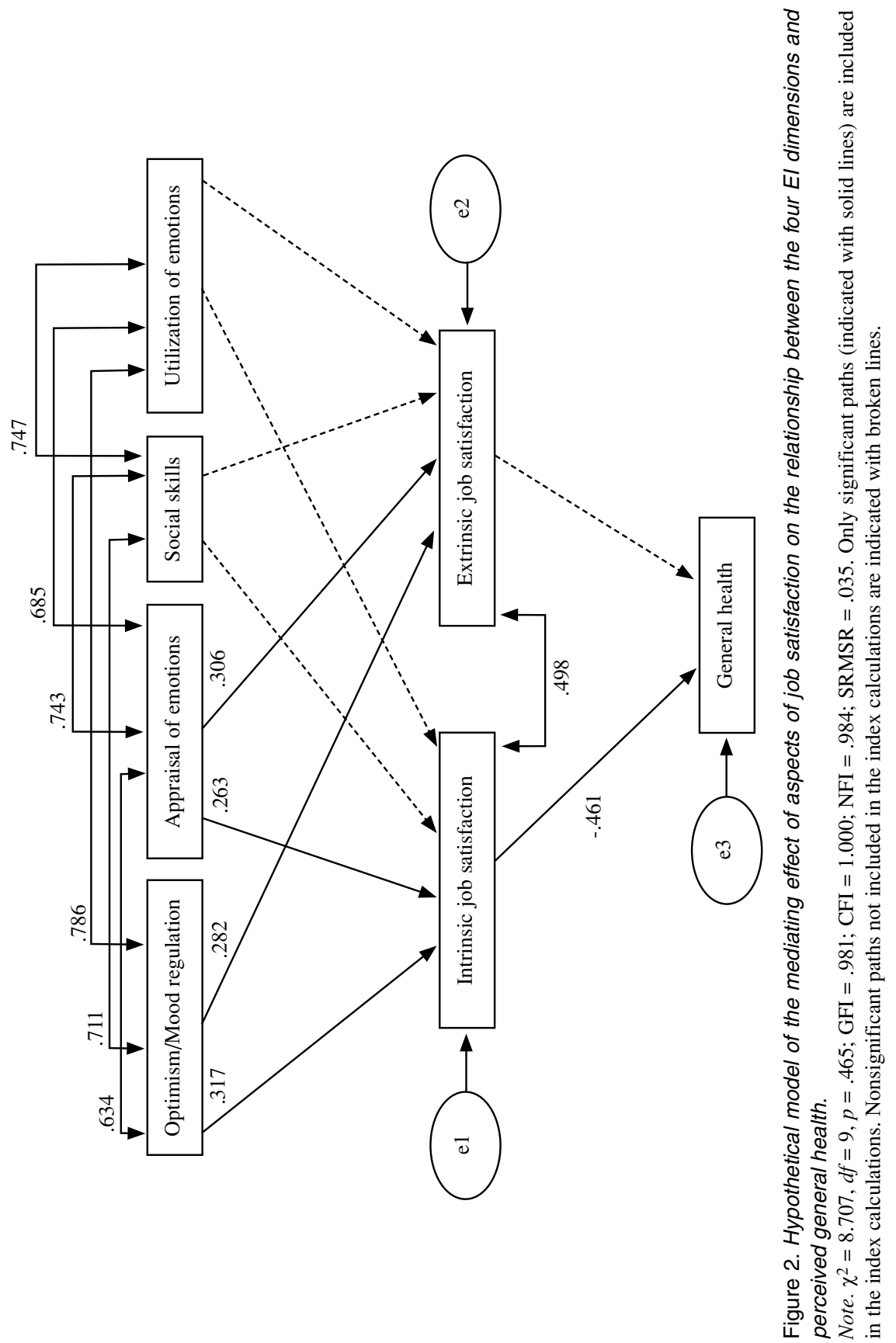
revealed that almost all of the model's fit indices were good, and there were significant path coefficients, indicating that the model fitted very well with the data. Intrinsic job satisfaction was a significant mediator in the relationship between the OMR and AOE dimensions of EI and perceived general health.

\section{Discussion}

In this study we found that the four dimensions of EI (OMR, AOE, SS, and UOE) were positively correlated with job satisfaction, supporting Hypothesis 1. In addition, job satisfaction was significantly and positively correlated with perceived general health, supporting Hypothesis 2. The SEM results further indicated that intrinsic job satisfaction was an important mediator of the relationship between EI and perceived general health, supporting Hypothesis 3 .

Our results support the notion that EI may have an influence on job satisfaction. The positive correlations we found between EI and job satisfaction were consistent with Wong and Law's (2002) report that employees with higher EI have greater job satisfaction, and also Ignat and Clipa's (2012) recent finding that teachers with a high level of EI had a more positive attitude toward work and were more satisfied with their work, than were teachers with low EI. In addition, our findings were in agreement with those of Kawada and Yamada (2012), that workers with high levels of job satisfaction tended to have better general health.

According to the partial correlation result, EI may have an indirect beneficial effect on perceived general health. However, in the path model it was revealed that the effect of EI on perceived general health became significant only with the addition of job satisfaction. This offers a deeper insight into the relationship between EI and perceived general health than that offered in other studies, in which EI was directly correlated with other factors, such as perceived general health, performance, and leadership (Goleman, 1998; Slaski \& Cartwright, 2002).

A mediating effect of job satisfaction was found between only two dimensions of EI (OMR and AOE) and perceived general health. It is well known that effective emotion regulation results in an optimum level of physiological arousal, and influences employees' emotions and emotion expression (Cassidy, 1994). In a study focused on the mediating effect of job satisfaction on the relationship between EI and organizational commitment, Güleryüz et al. (2008) found that nurses with higher EI levels could manage their own feelings, and understand and deal effectively with others' feelings. Thus, these nurses were happier than others were and more committed to their organization. Similarly, results of our study showed that individuals with higher EI levels were more likely to have high levels of job satisfaction.

In addition, job satisfaction influences teachers' work performance. For example, Abouserie (1996) found that university faculty members were adept 
in using a wide range of coping strategies to gain greater job satisfaction, and that those with a higher level of education were more adept in managing their emotions, than were those with lower levels of education. In addition, the faculty members were also aware of the importance of their job, and how well it fitted in with their long-term aims, so they were more likely to be satisfied with their present jobs.

Furthermore, because employees with high EI tend to be satisfied with their life and have a positive attitude toward work, they may report a better perception of general health status (Arnold et al., 2005). This may explain why job satisfaction plays a mediating role in the relationship between EI and perceived general health.

Our findings have several important implications for management in Chinese medical universities. First, some medical universities conduct personality tests as part of human resource management activities, to help understand faculty members' motivation, innovation potential, interests, and attitudes. Our results could be used to assist in understanding the influence of EI on work satisfaction and perceived general health. Second, our results are informative for the design of intervention programs to improve work performance. Third, the mediating role of job satisfaction in the relationship between EI and perceived general health has implications for promoting general health of faculty members in Chinese medical universities.

There are several limitations in this study. First, as all the respondents belonged to a single institution, the results cannot be generalized to all universities. Second, as we did not include many factors that may affect the study variables, and all data were self-reported, our findings offer only a promising platform upon which to base future work. It would be useful to apply SEM to investigate the interrelationships among EI, job satisfaction, and perceived general health across different occupations to obtain more generalizable results.

\section{References}

Abouserie, R. (1996). Stress, coping strategies and job satisfaction in university academic staff. Educational Psychology: An International Journal of Experimental Educational Psychology, 16, 49-56. http://doi.org/bppt4c

Abraham, R. (2000). The role of job control as a moderator of emotional dissonance and emotional intelligence-outcome relationships. The Journal of Psychology: Interdisciplinary and Applied, 134, 169-184. http://doi.org/dk63c2

Arnold, J., Silvester, J., Patterson, F., Robertson, I., Cooper, C., \& Burnes, B. (2005). Work psychology: Understanding human behaviour in the workplace (4th ed.). London, UK: Pearson Education.

Bar-On, R. (1997a). The Bar-On Emotional Quotient Inventory (EQ-i): Technical manual. Toronto, ON, Canada: Multi-Health Systems. 
Bar-On, R. (1997b). The Emotional Intelligence Inventory (EQ-I): Technical manual. Toronto, ON, Canada: Multi-Health Systems.

Birks, Y. F., \& Watt, I. S. (2007). Emotional intelligence and patient-centred care. Journal of the Royal Society of Medicine, 100, 368-374. http://doi.org/fhfs2q

Birol, C., Atamtürk, H., Silman, F., \& Şensoy, S. (2009). Analysis of the emotional intelligence level of teachers. Procedia - Social and Behavioral Sciences, 1, 2606-2614. http://doi.org/bckbjd

Bowling, A. (1997). Measuring health: A review of quality of life measurement scales (2nd ed.). Buckingham, UK: Open University Press.

Cameron, A. (1999). WPQei user's guide. London, UK: The Test Agency.

Cassidy, J. (1994). Emotion regulation: Behavioral and biological considerations. In N. A. Fox (Ed.), Emotion regulation: Behavioral and biological considerations, Monographs of the Society for Research in Child Development (pp. 228-249). Chicago, IL: University of Chicago Press.

Dale, B., Sævareid, H. I., \& Söderhamn, O. (2009). Testing and using Goldberg's General Health Questionnaire: Mental health in relation to home nursing, home help, and family care among older, care-dependent individuals. International Journal of Mental Health Nursing, 18, 133-143. http://doi.org/d3ff2w

Duffield, C., Roche, M., O'Brien-Pallas, L., Catling-Paull, C., \& King, M. (2009). Staff satisfaction and retention and the role of the nursing unit manager. Collegian, 16, 11-17. http://doi.org/ c92ccd

Giriyappa, P., \& Sullivan, K. K. (2009). Career satisfaction and retention risk among Wisconsin internists. Wisconsin Medical Journal, 108, 316-320.

Goldberg, D. (1978). Manual of the General Health Questionnaire. Windsor, UK: National Foundation for Educational Research.

Goldberg, D., \& Williams, P. (1988). A user's guide to the General Health Questionnaire. Windsor, UK: National Foundation for Educational Research.

Goleman, D. (1998). Working with emotional intelligence. New York: Random House.

Güleryüz, G., Güney, S., Aydın, E. M., \& Aşan, O. (2008). The mediating effect of job satisfaction between emotional intelligence and organisational commitment of nurses: A questionnaire survey. International Journal of Nursing Studies, 45, 1625-1635. http://doi.org/bzf6gn

Hayne, A. N., Gerhardt, C., \& Davis, J. (2009). Filipino nurses in the United States: Recruitment, retention, occupational stress, and job satisfaction. Journal of Transcultural Nursing, 20, 313-322. http://doi.org/dzssxf

Herzberg, F. (1968). One more time: How do you motivate employees? Harvard Business Review, $46,53-62$.

Holmbeck, G. (1997). Toward terminological, conceptual, and statistical clarity in the study of mediators and moderators: Examples from the child-clinical and pediatric psychology literatures. Journal of Consulting and Clinical Psychology, 65, 599-610. http://doi.org/c2sh9h

Hoppock, R. (1935). Job satisfaction. New York: Harper and Row.

Ignat, A. A., \& Clipa, O. (2012). Teachers' satisfaction with life, job satisfaction and their emotional intelligence. Procedia - Social and Behavioral Sciences, 33, 498-502. http://doi.org/s4w

Jones, T. L., \& Argentino, D. (2010). Nurse-to-nurse hostility, confrontational anxiety, and emotional intelligence: An integral, descriptive pilot study. Journal of PeriAnesthesia Nursing, 25, 233-241. http://doi.org/frsv4z

Judge, T. A., Thoresen, C. J., Bono, J. E., \& Patton, G. K. (2001). The job satisfaction-job performance relationship: A qualitative and quantitative review. Psychological Bulletin, 127, 376-407. http://doi.org/bqbpgv

Kawada, T., \& Yamada, N. (2012). 100-point scale evaluating job satisfaction and the results of the 12-item General Health Questionnaire in occupational workers. Work: A Journal of Prevention, Assessment, and Rehabilitation, 42, 415-418. http://doi.org/s4x 
Locke, E. A. (1976). The nature and causes of job satisfaction. In M. D. Dunnette (Ed.), Handbook of industrial and organizational psychology (pp. 1297-1349). Chicago, IL: Rand McNally.

Mayer, J. D., Salovey, P., Caruso, D. R., \& Sitarenios, G. (2003). Measuring emotional intelligence with the MSCEIT V2.0. Emotion, 3, 97-105. http://doi.org/fpb3gp

Ríos-Risquez, M. I., \& Godoy-Fernández, C. (2008). Association between occupational satisfaction and perceived general health in emergency nurses. Enfermería Clínica, 18, 134-141. http://doi. org/ffr3bq

Robertson, I. T., Birch, A. J., \& Cooper, C. L. (2012). Job and work attitudes, engagement and employee performance: Where does psychological well-being fit in? Leadership \& Organization Development Journal, 33, 224-232. http://doi.org/tg3

Salovey, P., \& Mayer, J. D. (1990). Emotional intelligence. Imagination, Cognition and Personality, 9, 185-211. http://doi.org/d7s8wh

SAS Institute Inc. (2008). SAS/STAT® 9.2 user's guide. Cary, NC: SAS Institute Inc.

Schutte, N., Malouff, J., Hall, L., Haggerty, D., Cooper, J., Golden, C., \& Dornheim, L. (1998). Development and validation of a measure of emotional intelligence. Personality and Individual Differences, 25, 167-177. http://doi.org/fmng7.j

Slaski, M., \& Cartwright, S. (2002). Health, performance and emotional intelligence: An exploratory study of retail managers. Stress and Health, 18, 63-68. http://doi.org/fhg4dn

Tsai, M.-T., \& Hsu, Y.-T. (2008). A resource-based perspective on retention strategies for nurse epidemiologists. Journal of Advanced Nursing, 61, 188-200. http://doi.org/c4ppxm

Weiss, D., Dawis, R., England, G., \& Lofquist, L. H. (1967). Manual for the Minnesota Satisfaction Questionnaire. Minneapolis, MN: University of Minnesota.

Wong, C.-S., \& Law, K. (2002). The effect of leader and follower emotional intelligence on performance and attitude: An exploratory study. The Leadership Quarterly, 13, 243-274. http:// doi.org/cz3

Wright, T. A., \& Cropanzano, R. (2000). Psychological well-being and job satisfaction as predictors of job performance. Journal of Occupational Health Psychology, 5, 84-94. http://doi.org/bc9ncb

Zeidner, M., Matthews, G., \& Roberts, R. (2004). Emotional intelligence in the workplace: A critical review. Applied Psychology, 53, 371-399. http://doi.org/fwct3v 